Rapid Reviews COVID-19

\title{
Reviews of "Developing an accuracy-prompt toolkit to reduce COVID-19 misinformation online"
}

Bahiyah Omar' ${ }^{1}$, Akshaya Bhagavathula ${ }^{2}$

${ }^{1}$ Universiti Sains Malaysia, School of Communication, Malaysia,

${ }^{2}$ UAE University: United Arab Emirates University, Public Health

Published on: May 07, 2021

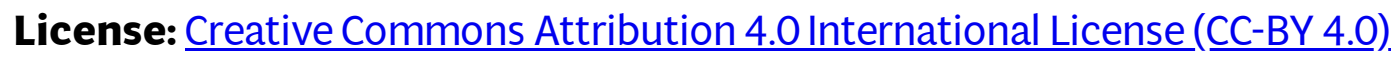


To read the original manuscript, click the link above.

Summary of Reviews: Paying attention to the accuracy of information will increase sharing discernment on social media, which reduces misinformation spread online. Both reviewers found the paper potentially informative, but one reviewer was concerned about the claims made based on its methodology.

\section{Reviewer 1 (Bahiyah Omar) | प्राप}

\section{Reviewer 2 (Akshaya Bhagavathula)}

$$
\begin{aligned}
& \text { RR:C19 Strength of Evidence Scale Key } \\
& \text { प्रमप = Misleading }
\end{aligned}
$$

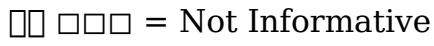

$$
\begin{aligned}
& \text { प्रा पि = Potentially Informative }
\end{aligned}
$$

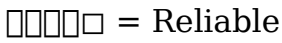

$$
\begin{aligned}
& \text { प्राप्र = Strong }
\end{aligned}
$$

To read the reviews, click the links below. 